Case Report

\title{
Acquired Von Willebrand's Syndrome in Systemic Lupus Erythematosus
}

\author{
Sara Taveras Alam, ${ }^{1}$ Karenza Alexis, ${ }^{2}$ Ashwin Sridharan, ${ }^{2}$ Marianna Strakhan, ${ }^{2}$ \\ Tarek Elrafei, ${ }^{2}$ Richard J. Gralla, ${ }^{2}$ and Louis J. Reed ${ }^{2}$ \\ ${ }^{1}$ Department of Internal Medicine, Albert Einstein College of Medicine, Jacobi Medical Center, Bronx, NY 10461, USA \\ ${ }^{2}$ Division of Hematology and Oncology, Albert Einstein College of Medicine, Jacobi Medical Center and Montefiore Medical Center, \\ Bronx, NY 10461, USA
}

Correspondence should be addressed to Sara Taveras Alam; sarataveras@gmail.com

Received 23 July 2014; Accepted 13 November 2014; Published 7 December 2014

Academic Editor: Marie-Christine Kyrtsonis

Copyright (C) 2014 Sara Taveras Alam et al. This is an open access article distributed under the Creative Commons Attribution License, which permits unrestricted use, distribution, and reproduction in any medium, provided the original work is properly cited.

Acquired von Willebrand syndrome (AVWS) is an uncommon, underdiagnosed, and heterogeneous disease which is increasingly recognized as a cause of bleeding diatheses. Systemic lupus erythematosus (SLE) is an infrequent cause of AVWS. Herein, we report a case of AVWS diagnosed during the initial presentation of SLE in a previously healthy young man with no family history of bleeding diathesis who presented with worsening epistaxis, gastrointestinal bleeding, and anasarca. He was found to have severe anemia and prolonged activated partial thromboplastin time (aPTT) with severely decreased levels of von Willebrand factor (VWF) measurements in addition to markedly decreased factor VIII levels. Further evaluation revealed nephrotic syndrome and interstitial lung disease due to SLE. He initially received combination therapy with intravenous immunoglobulin (IVIG) and von Willebrand factor/factor VIII concentrates without significant improvement. Treatment with steroids, cyclophosphamide, and rituximab was followed by clinical improvement evidenced by cessation of bleeding. The short follow-up did not allow us to definitely prove the therapeutic effect of immunosuppressive treatment on AVWS in SLE patients. This case adds to the literature supporting the relationship between AVWS and SLE and highlights the importance of combination therapy in the treatment of severe AVWS as well as the role of IVIG, cyclophosphamide, and rituximab in AVWS associated with SLE.

\section{Introduction}

Acquired von Willebrand syndrome (AVWS) is a rare but increasingly recognized cause of bleeding diathesis. It should be suspected in patients with mucocutaneous bleeding without a prior personal or family history of bleeding disorders and an isolated elevated activated partial thromboplastin time. Systemic lupus erythematosus (SLE) is an infrequent cause of AVWS, but associations between these two diseases have been documented and described in the literature [1-18]. Herein, we present a case of severe AVWS diagnosed during the initial presentation of SLE in a previously healthy young man.

\section{Case Report}

A 26-year-old Mexican male with no significant past medical history other than a childhood appendectomy presented to the emergency department after several weeks of worsening epistaxis. He also admitted to have easy bruising, 1-2 episodes of tarry stools, lower extremity swelling, and increased abdominal girth during this time, as well as fatigue and decreased exercise tolerance.

He denied prior bleeding or family history of bleeding disorders or autoimmune conditions.

Physical exam was significant for pallor, periorbital edema, dried blood in the vestibule of right nostril and red blood to the left nostril, and petechiae to the soft palate without notable bleeding in the oropharynx. Also noted on exam were elevated jugular venous pressure, tachycardia at 110 beats per minute, decreased breath sounds on the right lung base, abdominal distension with dullness to percussion, and bilateral $2+$ pitting lower extremity edema up to the thighs. Stool guaiac performed in the emergency department was positive. 
TABLE 1: Laboratory data of patient.

\begin{tabular}{|c|c|c|c|}
\hline & Initial & Final $^{\wedge}$ & Reference values \\
\hline WBC & $11.0 / \mathrm{nL}$ & $7.8 / \mathrm{nL}$ & $3.9-10.6 / \mathrm{nL}$ \\
\hline $\mathrm{Hb}$ & $4.6 \mathrm{~g} / \mathrm{dL}$ & $8.1 \mathrm{~g} / \mathrm{dL}$ & $13.5-17.5 \mathrm{~g} / \mathrm{dL}$ \\
\hline Hct & $14.20 \%$ & $25.80 \%$ & $41-53 \%$ \\
\hline Plt & $112 / \mathrm{nL}^{*}$ & $450 / \mathrm{nL}$ & $150-440 / \mathrm{nL}$ \\
\hline INR & 1.06 & 1.00 & $0.9-1.2$ \\
\hline aPTT & $50.6 \mathrm{sec}$ & $43.7 \mathrm{sec}$ & $20.1-31.2 \mathrm{sec}$ \\
\hline Fibrinogen & $308 \mathrm{mg} / \mathrm{dL}$ & NT & $200-400 \mathrm{mg} / \mathrm{dL}$ \\
\hline VWF : Ag & $8 \%$ & $10 \%$ & $5-217 \%$ \\
\hline VWF: RCo & $0 \%$ & $0 \%$ & $50-150 \%$ \\
\hline FVIII : C & $2 \%$ & $6 \%$ & $60-150 \%$ \\
\hline $\mathrm{Cr}$ & $0.9 \mathrm{mg} / \mathrm{dL}$ & $0.8 \mathrm{mg} / \mathrm{dL}$ & $0.1-1.5 \mathrm{mg} / \mathrm{dL}$ \\
\hline Albumin & $1.1 \mathrm{~g} / \mathrm{dL}$ & $2.5 \mathrm{~g} / \mathrm{dL}$ & $3.5-5.5 \mathrm{~g} / \mathrm{dL}$ \\
\hline Protein/Cr ratio & $2477 \mathrm{mg} / \mathrm{g}$ & NT & $\leq 84 \mathrm{mg} / \mathrm{g}$ \\
\hline ANA & 1:320, homogeneous & NT & $<1: 80$ \\
\hline Anti-dsDNA & $344 \mathrm{IU} / \mathrm{mL}$ & NT & $\leq 99 \mathrm{IU} / \mathrm{mL}$ \\
\hline $\mathrm{C} 3$ & $<30 \mathrm{mg} / \mathrm{dL}$ & NT & $90-180 \mathrm{mg} / \mathrm{dL}$ \\
\hline $\mathrm{C} 4$ & $<6 \mathrm{mg} / \mathrm{dL}$ & NT & $10-40 \mathrm{mg} / \mathrm{dL}$ \\
\hline CRP & $5.7 \mathrm{mg} / \mathrm{L}$ & NT & $0-5.0 \mathrm{mg} / \mathrm{L}$ \\
\hline ESR & $100 \mathrm{~mm} / \mathrm{h}$ & NT & $0-15 \mathrm{~mm} / \mathrm{h}$ \\
\hline Reticulocytes & $3.21 \%$ & NT & $0.5-2 \%$ \\
\hline $\mathrm{LDH}$ & $290 \mathrm{U} / \mathrm{L}$ & NT & $100-210 \mathrm{U} / \mathrm{L}$ \\
\hline Haptoglobin & $219 \mathrm{mg} / \mathrm{dL}$ & NT & $43-212 \mathrm{mg} / \mathrm{dL}$ \\
\hline Total bilirubin & $0.1 \mathrm{mg} / \mathrm{dL}$ & NT & $0.1-1.2 \mathrm{mg} / \mathrm{dL}$ \\
\hline AST & $19 \mathrm{U} / \mathrm{L}$ & NT & $1-40 \mathrm{U} / \mathrm{L}$ \\
\hline ALT & $9 \mathrm{U} / \mathrm{L}$ & NT & $1-40 \mathrm{U} / \mathrm{L}$ \\
\hline ALP & $49 \mathrm{U} / \mathrm{L}$ & NT & 30-115 U/L \\
\hline Direct Coombs test & Negative & NT & Negative \\
\hline TSH & $10.773 \mathrm{mIU} / \mathrm{L}$ & NT & $0.47-6.90 \mathrm{mIU} / \mathrm{L}$ \\
\hline Free T4 & $1.19 \mathrm{ng} / \mathrm{dL}$ & NT & $0.74-2 \mathrm{ng} / \mathrm{dL}$ \\
\hline
\end{tabular}

WBC: white blood cell count; Hb: hemoglobin; Hct: hematocrit; Plt: platelet count; INR: international normalized ration; aPTT: activated partial thromboplastin time; VWF: Ag: von Willebrand factor antigen; VWF: RCo: von Willebrand factor ristocetin cofactor; FVIII : C: factor VIII procoagulant activity; Cr: creatinine; NT: not tested; ANA: antinuclear antibodies; anti-dsDNA: anti-double stranded DNA antibodies; C3: complement component 3; C4: complement component 4; CRP: C reactive protein; ESR: erythrocyte sedimentation rate; LDH: lactate dehydrogenase; AST: aspartate aminotransferase; ALT: alanine aminotransferase; ALP: alkaline phosphatase; TSH: thyroid stimulating hormone.

$\wedge$ At last follow-up.

${ }^{*}$ Plt decreased to $86 / \mathrm{nL}$ on the 4 th day of admission.

On initial laboratory evaluation, the patient was found to have severe normocytic anemia with hemoglobin $(\mathrm{Hb})$ of $4.6 \mathrm{~g} / \mathrm{dL}$ (MCV $87 \mathrm{fL}$, RDW 18.9\%, reticulocytes $2.79 \%$ ) and a prolonged activated partial thromboplastin time (aPTT) at $50.6 \mathrm{sec}$ with a normal prothrombin time. Initial laboratory testing was also remarkable for thrombocytopenia at $112 / \mathrm{nL}$ and severe hypoalbuminemia at $1.1 \mathrm{~g} / \mathrm{dL}$; see Table 1 for reference values. Fibrinogen levels were within normal limits and LDH was only mildly elevated at $290 \mathrm{U} / \mathrm{L}$ (normal range 140-280 U/L). Peripheral blood smear was remarkable only for mild thrombocytopenia.

Four units of packed red blood cells (PRBCs) were administered with subsequent $\mathrm{Hb}$ increase to only $6.7 \mathrm{~g} / \mathrm{dL}$, corroborating significant active bleeding. Two units of fresh frozen plasma (FFP) were given without improvement in his coagulation profile and hematological opinion was requested to further evaluate coagulopathy.
Subsequent testing demonstrated normal factor IX and factor XI levels but factor VIII was markedly decreased at $2 \%$ (normal range $60-150 \%$ ) and von Willebrand factor activity/Ristocetin cofactor was undetectable ( $0 \%$, normal range 50-150\%). Von Willebrand factor antigen (VWF Ag) was also low at $8 \%$ (normal range $50-217 \%$ ). Acquired von Willebrand's syndrome was diagnosed. Inherited type III VWD was deemed unlikely given history of appendectomy without bleeding complications. Given clinical suspicion of AVWS, he received loading dose of VWF containing concentrate (Humate-P, which was given at $40 \mathrm{U} / \mathrm{kg}$ ) along with intravenous immune globulin (IVIG) at $400 \mathrm{mg} / \mathrm{kg}$ with a plan to give one dose a day over three days. Mixing study was unfortunately not performed prior to FFP administration, which did correct aPTT from 41 to 31 . Yet VWF activity and factor VIII levels continued to be low despite treatment with VWF containing concentrate, supporting the presence 
of a factor VIII inhibitor. The patient continued to have some epistaxis after initial VWF containing concentrate and IVIG. Consequently, IVIG was increased to $1 \mathrm{~g} / \mathrm{kg} / \mathrm{d}$ on day 2 of treatment and VWF containing concentrate dosing was also increased with eventual bleeding control. VWF activity persisted at $0 \%$ despite three days of IVIG and ten doses of VWF containing concentrate.

Hypoalbuminemia and anasarca in the absence of liver disease prompted workup for nephrotic syndrome. The patient was found to have near nephrotic range proteinuria (Prot/Cr ratio $2477 \mathrm{mg} / \mathrm{g}$ ) and dyslipidemia (HDL $9.9 \mathrm{mg}$ / dL). Abdominal US confirmed mild-to-moderate ascites and mild-to-moderate increased renal cortical echogenicity bilaterally as well as subcapsular edema of both kidneys. All of these findings were in fact consistent with nephrotic syndrome.

Renal biopsy was deferred due to bleeding diathesis. Hepatitis and syphilis serologies as well as rapid oral HIV antibody test were negative. Serum protein electrophoresis (SPEP) and urine protein electrophoresis (UPEP) did not show monoclonal bands; antineutrophil cytoplasmic antibodies (pANCA and cANCA) and glomerular basement membrane antibodies (GBM Ab) were negative. Complement levels were markedly decreased $(\mathrm{C} 3<30 \mathrm{mg} / \mathrm{dL}$ and $\mathrm{C} 4<$ $6 \mathrm{mg} / \mathrm{dL})$. Antinuclear antibody panel was significant for a positive dsDNA $\mathrm{Ab}(344 \mathrm{IU} / \mathrm{mL})$ and low positive histone $\mathrm{Ab}(142 \mathrm{IU} / \mathrm{mL})$; however the patient had not been on medications prior to admission to suggest drug induced lupus. Antinuclear antibody was positive at $1: 320$, with a homogeneous pattern. Cardiolipin IgM/IgG and lupus anticoagulant were negative. Rheumatology consultation recommended initiation of stress dose steroids as well as obtaining high resolution chest computerized tomography, which demonstrated central ground glass opacities.

The patient met criteria for systemic lupus erythematosus (SLE) based on Lupus International Collaborating Clinics Classification criteria due to positive ANA titer, positive antidsDNA, low C3 and C4 levels, and thrombocytopenia and renal involvement.

In total, the patient received 5 units of PRBCs, 2 units of FFP, 15 doses of VWF containing concentrate, IVIG for 3 days ( $30 \mathrm{~g}$ IVSS on day $1,75 \mathrm{~g}$ IVSS on day 2 , and $45 \mathrm{~g}$ IVSS on day 3 for $2 \mathrm{~g} / \mathrm{kg}$ total dose), and pulse steroids (solumedrol $1 \mathrm{~g}$ per day for 3 days and then solumedrol $80 \mathrm{mg}$ per day for 2 days) that were switched to maintenance prednisone $60 \mathrm{mg}$ po daily thereafter. He also received a single dose of desmopressin $22.5 \mathrm{mcg}$ without improvement in his laboratory values. Nephrotic syndrome was managed with diuretics and antihypertensives including ACE inhibitors. On day 8 of treatment, he was given one dose of IV cyclophosphamide $(750 \mathrm{mg}$ IVSS) and one dose of rituximab (375 mg/kg IVSS) with subsequent clinical improvement. The patient was discharged in stable condition and on outpatient follow-up reported only minimal self-remitting epistaxis since his discharge.

The patient received a total of four weekly doses of rituximab $375 \mathrm{mg} / \mathrm{m}^{2}$. One month after presentation, anasarca and hypoalbuminemia improved (albumin $2.5 \mathrm{~g} / \mathrm{dL}$ ), $\mathrm{Hb}$ had remained stable at $8.1 \mathrm{~g} / \mathrm{dL}$ without signs of bleeding, and thrombocytopenia resolved. VW factor activity however remained at $0 \%$. He has since then been lost to follow-up, limiting further assessment of his response.

\section{Discussion}

AVWS is an uncommon, underdiagnosed, and heterogeneous disease which is more frequently being recognized as a cause of bleeding diatheses [1,19-22]. Most cases present with mild-to-moderate mucocutaneous bleeding in the absence of a personal or family history of bleeding. Laboratory findings are similar to those of congenital von Willebrand disease (VWD), frequently with a prolonged bleeding time and low levels of von Willebrand factor measurements (VWFAg, functional assays and/or abnormal VWF multimers). Some cases have borderline to normal values of VWF functional assays, with a ratio to VWF Ag less than 0.7 indicating inhibitory antibodies or decrease in high molecular weight multimers, whereas under normal conditions VWF : $\mathrm{RCo} / \mathrm{Ag}$ ratio or $\mathrm{VWF}: \mathrm{CBA} / \mathrm{Ag}$ ratio should be close to one [18]. Factor VIII may be decreased and activated partial thromboplastin time may be prolonged, as was the case in our patient.

Literature review suggests that, with the exception of patients with AVWS associated with hypothyroidism, low levels of VWF in AVWS are due to accelerated removal of the protein from the plasma via one of five described mechanisms: (1) specific autoantibodies that inactivate or increase the clearance of FVIII/VWF; (2) nonspecific antibodies that form circulating complexes with VWF, which are then cleared by Fc-bearing cells; (3) absorption of VWF onto malignant cell clones or platelets; (4) increased proteolytic degradation of VWF; or (5) loss of VWF multimers in high shear stress conditions [18, 23-27]. Only a minority of cases are due to factor VIII/von Willebrand factor-inhibiting activities [28], which alongside increased clearance due to antibody complexes represent the plausible explanations for AVWS in patients with SLE.

An international registry of 186 collected cases published in 2000 reported that the most common disorders associated with acquired von Willebrand syndrome were, in order of decreasing frequency: lymphoproliferative, cardiovascular, and myeloproliferative disease, as well as neoplasias. Other reported underlying conditions include drugs, infectious diseases, uremia, and hypothyroidism. Immune-mediated underlying causes are less common and only accounted for $2 \%$ of registry cases and $6 \%$ of cases found upon literature review at that time [25]. A follow-up publication four years later recognized that there may have been a bias towards disproportionately fewer cases of AVWS reported in association with immunologic disorders in the registry due to the low participation of immunologists or rheumatologists [26]. Besides SLE, other immunologic disorders that have been reported to be associated with AVWS include mixed connective tissue disease, scleroderma, Sjogren's syndrome, antiphospholipid syndrome, and graft versus host disease $[12,17,29,30]$.

The association between SLE and AVWS was first described in a 12-year-old boy with lupus nephritis in 1968 
TABLE 2: AVWS in cases associated with SLE or lupus-like serology published to present date.

\begin{tabular}{|c|c|}
\hline Author (Year) & Title \\
\hline Simone et al. (1968) [14] & Acquired von Willebrand's syndrome in systemic lupus erythematosus \\
\hline Ingram et al. (1971) [8] & Four cases of acquired von Willebrand's syndrome ${ }^{*}$ \\
\hline Poole-Wilson (1972) [13] & Acquired von Willebrand's syndrome and systemic lupus erythematosus \\
\hline Gazengel et al. (1978) [3] & $\begin{array}{l}\text { Antibody-induced von Willebrand syndrome: inhibition of VIII VWF and VIII AGN with sparing } \\
\text { of VIII AHF by the autoantibody }\end{array}$ \\
\hline Pizzuto et al. (1980) [12] & Acquired von Willebrand's syndrome during autoimmune disorder \\
\hline Yoshida et al. (1988) [17] & Development of acquired von Willebrand's disease after mixed connective tissue disease \\
\hline Igarashi et al. (1989) [7] & Acquired von Willebrand's syndrome with lupus-like serology \\
\hline Soff and Green (1993) [15] & Autoantibody to von Willebrand factor in systemic lupus erythematosus \\
\hline Hanley et al. (1994) [5] & $\begin{array}{l}\text { Acquired von Willebrand's syndrome in association with a lupus-like anticoagulant corrected by } \\
\text { intravenous immunoglobulin }\end{array}$ \\
\hline Jackson et al. (1995) [9] & $\begin{array}{l}\text { Puerperal acquired factor VIII inhibitor causing a von Willebrand-like syndrome in a patient with } \\
\text { anti-DNA antibodies }\end{array}$ \\
\hline Viallard et al. (1999) [16] & Three cases of acquired von Willebrand disease associated with systemic lupus erythematosus ${ }^{* * *}$ \\
\hline Niiya et al. (2002) [11] & Acquired type 3-like von Willebrand syndrome preceded full-blown systemic lupus erythematosus \\
\hline Casonato et al. (2002) [2] & Lack of multimer organization of von Willebrand factor in an acquired von Willebrand syndrome \\
\hline Tiede et al. (2008) [18] & $\begin{array}{l}\text { Diagnostic workup of patients with acquired von Willebrand syndrome: a retrospective } \\
\text { single-center cohort study** }\end{array}$ \\
\hline Hong et al. (2008) [6] & Systemic lupus erythematosus complicated by acquired von Willebrand's syndrome \\
\hline Kasatkar et al. (2013) [1] & Acquired von Willebrand syndrome: a rare disorder of heterogeneous etiology ${ }^{* * *}$ \\
\hline Jimenez et al. (2013) [10] & $\begin{array}{l}\text { Rituximab effectiveness in a patient with juvenile systemic lupus erythematosus complicated with } \\
\text { acquired Von Willebrand syndrome }\end{array}$ \\
\hline Hami et al. (2014) [4] & $\begin{array}{l}\text { Acquired von Willebrand syndrome in a male with systemic lupus erythematosus presented with } \\
\text { mucocutaneous bleeding and was treated with rFVIIa }\end{array}$ \\
\hline
\end{tabular}

[14]. To this date, on our review of the literature, close to 700 AVWS cases have been reported $[18,25,31,32]$ and approximately twenty cases have been associated with SLE or lupus-like connective tissue disorder (see Table 2). Michiels has reported the presentation and course of all cases in the English language literature of AVWS and systemic lupus erythematosus up until 2001 [33]. In total, 12 cases were described $[3,5,7,8,12-17]$. Since 2001, there have been at least nine other reported cases of AVWS associated with SLE, including one patient with SLE in a retrospective singlecenter cohort study of 35 patients diagnosed with AVWS at Hannover Medical School [1, 2, 4, 6, 10, 11, 18, 34]. Most cases present at the time a patient is diagnosed with SLE or in patients already diagnosed with SLE. However, it has also been reported as a "herald" syndrome in a patient who later developed this disease $[1,11,14,16]$. This raises the question of whether the published cases with lupus-like features that did not meet SLE diagnosis criteria in full $[5,7,9]$ would have developed florid SLE with time if the disease was not treated or if there had been longer follow-up.

It is important to note that permanent reversal of the bleeding disorder may occur with treatment of the associated disease. Therefore, a reasonable workup for such associated diseases should be undertaken in any patient with AVWS [35]. In fact, bleeding symptoms due to AVWS can establish the need for treating an underlying disorder that otherwise may not have been treated, like monoclonal gammopathy of unknown significance [18].

In addition to aiming treatment of AVWS at the underlying cause or associated disease when possible, efforts should also focus on controlling and preventing bleeding episodes. Due to the heterogeneity of AVWS, no single drug is effective for all cases [36]. Accordingly, treatment usually involves a customized combination of available options: DDAVP, FVIII/VWF concentrates, high dose intravenous immunoglobulin (IVIG), plasmapheresis, corticosteroids, and immunosuppressive or chemotherapeutic agents. Recombinant factor VIIa has also been used in resistant cases [4] and antifibrinolytics have been used as adjunct therapies in cases associated with bleeding in areas of increased fibrinolysis. In AVWS associated with SLE, response to DDAVP and VWF/FVII is poor whereas IVIG has been effective and corticosteroids may provide cure [37]. Chemotherapeutic agents such as cyclophosphamide and rituximab have been of use in a few cases $[10,16,22,38,39]$; see Table 3.

The effect of desmopressin in AVWS is of lesser magnitude compared to congenital VWD because the increase in the VWF-FVIII complex is short-lived due to autoantibodies or increased clearance [40]. VWF containing concentrates, despite being more effective than DDAVP for AVWS, may 
TABLE 3: Therapeutic options in acquired von Willebrand syndrome associated with SLE.

\begin{tabular}{|c|c|c|}
\hline Therapeutic option & Dose & Comment \\
\hline Desmopressin & $\begin{array}{l}0.3 \mu \mathrm{g} / \mathrm{kg} \text { over } 30 \text { minutes } \\
\text { once or twice daily }\end{array}$ & Limited response, use in combination with IVIG \\
\hline $\begin{array}{l}\text { VWF containing } \\
\text { concentrates }\end{array}$ & 30-100 VWF : RCo units/kg & $\begin{array}{l}\text { Dose depending on the patient's residual activity, severity of bleeding, and presence } \\
\text { of inhibitors; also limited response, use in combination with IVIG }\end{array}$ \\
\hline $\begin{array}{l}\text { Recombinant factor } \\
\text { VIIa }\end{array}$ & $\begin{array}{l}90 \mu \mathrm{g} / \mathrm{kg} \text { (range: } \\
40-150 \mu \mathrm{g} / \mathrm{kg} \text { ) every } 2-6 \\
\text { hours }\end{array}$ & $\begin{array}{l}\text { For a median of } 3 \text { doses } \\
\text { (range } 1-54 \text { doses) }\end{array}$ \\
\hline IVIG & $1 \mathrm{~g} / \mathrm{kg} / \mathrm{d}$ for 2 days & $\begin{array}{l}\text { May repeat a single high-dose } 1 \mathrm{~g} / \mathrm{kg} / \mathrm{d} \text { every } 21 \text { days; use of desmopressin and VWF } \\
\text { containing concentrates is recommended initially for bleeding control as response } \\
\text { is not immediate }\end{array}$ \\
\hline Steroids & $\begin{array}{l}\text { Prednisone } 30-40 \mathrm{mg} / \mathrm{d} \text { or } \\
1-2 \mathrm{mg} / \mathrm{kg} \text { per day }\end{array}$ & It treats underlying cause \\
\hline Cyclophosphamide & $700 \mathrm{mg} / \mathrm{m}^{2}$ & $\begin{array}{l}\text { It treats underlying cause; single doses have been effective but treatment may be } \\
\text { repeated monthly }\end{array}$ \\
\hline Rituximab & $\begin{array}{l}375 \mathrm{mg} / \mathrm{m}^{2} \text { weekly for } 2-4 \\
\text { weeks }\end{array}$ & $\begin{array}{l}\text { Has been followed by doses every } 90 \text { days as long-term management in AVWS } \\
\text { associated with B cell lymphoma }\end{array}$ \\
\hline
\end{tabular}

IVIG: intravenous immunoglobulin.

also have a short half-life in patients with inhibitors [37]. Large doses may be required to overwhelm the autoantibody against exogenous VWF provided by the concentrates or to counterbalance the accelerated clearance of the VWF-FVIII complex [27].

IVIG has been described to temporarily normalize factor VIIIc and VWF levels $[5,16]$, especially in cases characterized by anti-FVIII/VWF inhibitors [40]. The underlying mechanism has been proposed to be related to immunoglobulin mediated elimination of circulating immune complexes, antiidiotype effect, direct inhibitory effect on the cells producing the anti-VWF antibody, or blockage of reticuloendothelial Fcreceptors preventing phagocytosis and clearance of antibodyantigen complexes [41, 42]. Although IVIG can produce a more sustained response than DDAVP or factor concentrates, it requires 24-48 hours to normalize plasma VWF-FVIII activity; thus DDAVP or VWF-FVIII concentrates can be given together with IVIG to achieve hemostasis immediately in cases of emergency bleeding $[22,25]$. Repeated doses of IVIG every 21 days can produce consistent responses, as has been shown in patients with IgG-MGUS [41, 43].

Steroids have been shown to be effective in most reported cases of AVWS associated with SLE, including the first case ever described $[1,3,6-8,11,13-17,34]$. In addition, adjuvant single doses of cyclophosphamide $\left(700 \mathrm{mg} / \mathrm{m}^{2}\right)$ have assisted in correcting factor VIII and VWF levels to reference values in a case with incomplete response to steroids [16].

Rituximab has known efficacy in treating acquired factor VIII inhibitors [44] and, although it has been ineffective in AVWS associated with MGUS, it has been shown to be effective for AVWS associated with B cell lymphoma or multiple myeloma [22, 38, 39]. It has also been reported to be effective in AVWS associated with juvenile SLE, following failure to respond to treatment with first and second line therapies [10]. The role of rituximab in AVWS may go beyond its part in treating the underlying disease. In cases related to antibody induced clearance of factor VIII/VWF, its effectiveness is possibly due to its anti-CD20 properties, specifically depleting $B$ cells, and possible blockage of the macrophage Fc-receptor function by rituximab-opsonized B cells [45].

Our patient initially received combination therapy with IVIG and VWF-FVIII concentrates without significant improvement. He then received steroids, cyclophosphamide, and rituximab with clinical improvement. Interestingly however, his von Willebrand factor measurements were not documented to have been corrected despite his clinical improvement. This may have been related to limited followup after treatment.

\section{Summary}

A case of severe AVWS diagnosed concurrently with newly diagnosed SLE in a previously healthy young man is described. This case supports the previously described intimate association between AVWS and SLE, the need for combination therapy, and the fact that reversal of the bleeding disorder may occur with treatment of the associated disease. In any patient with AVWS, in addition to treatment of the bleeding diathesis, a search for an underlying associated disease should be undertaken. Treatment should be primarily aimed at the underlying disorder, if found.

In our review of the literature, only approximately 20 cases of the close to 700 reported cases of AVWS have been associated with SLE. AVWS may present concurrently with SLE or in a patient already diagnosed with SLE and has also been described as a "herald syndrome" in patients who later develop lupus. The pathophysiology of this association is likely related to increased clearance of factor VIII/von Willebrand factor via antibodies or factor VIII/von Willebrand factor-inhibiting activities. In AVWS associated with SLE, response to DDAVP and VWF/FVIII is poor, whereas IVIG has been effective and corticosteroids may provide cure. Chemotherapeutic agents such as cyclophosphamide 
and rituximab may be required after failure to respond to other therapies.

\section{Conflict of Interests}

The authors declare that there is no conflict of interests regarding the publication of this paper.

\section{References}

[1] P. Kasatkar, K. Ghosh, and S. Shetty, "Acquired von Willebrand syndrome: a rare disorder of heterogeneous etiology," Journal of Postgraduate Medicine, vol. 59, no. 2, pp. 98-101, 2013.

[2] A. Casonato, E. Pontara, A. Doria et al., "Lack of multimer organization of von Willebrand factor in an acquired von Willebrand syndrome," British Journal of Haematology, vol. 116, no. 4, pp. 899-904, 2002.

[3] C. Gazengel, A. M. Prieur, C. Jacques, D. Buriot, J. Nedellec, and F. Josso, "Antibody-induced von Willebrand syndrome: inhibition of VIII VWF and VIII AGN with sparing of VIII AHF by the autoantibody," American Journal of Hematology, vol. 5, no. 4, pp. 355-363, 1978.

[4] M. Hami, H. Ahmadnia, Z. Rezaieyazdi, and H. Mansouritorghabeh, "Acquired von Willebrand syndrome in a male with systemic Lupus Erythematosus presented with Mucocutaneous bleeding and treated with rFVIIa," International Journal of Clinical Medicine, no. 5, pp. 23-27, 2014.

[5] D. Hanley, Y. S. Arkel, J. Lynch, and M. Kamiyama, "Acquired von Willebrand's syndrome in association with a lupus-like anticoagulant corrected by intravenous immunoglobulin," The American Journal of Hematology, vol. 46, no. 2, pp. 141-146, 1994.

[6] S. C. Hong, J. H. Lee, H. S. Chi et al., "Systemic lupus erythematosus complicated by acquired von Willebrand's syndrome," Lupus, vol. 17, no. 9, pp. 846-848, 2008.

[7] N. Igarashi, M. Miura, E. Kato et al., "Acquired von Willebrand's syndrome with lupus-like serology," The American Journal of Pediatric Hematology/Oncology, vol. 11, no. 1, pp. 32-35, 1989.

[8] G. I. Ingram, P. J. Kingston, J. Leslie, and E. J. Bowie, "Four cases of acquired von Willebrand's syndrome.," British Journal of Haematology, vol. 21, no. 2, pp. 189-199, 1971.

[9] N. Jackson, Z. A. Hashim, N. A. Zainal, and N. Jamaluddin, "Puerperal acquired factor VIII inhibitor causing a von Willebrand-like syndrome in a patient with anti-DNA antibodies," Singapore Medical Journal, vol. 36, no. 2, pp. 230-231, 1995.

[10] A. R. T. Jimenez, E. S. Vallejo, M. Z. Cruz, A. C. Cruz, J. V. R. Miramontes, and B. S. Jara, "Rituximab effectiveness in a patient with juvenile systemic lupus erythematosus complicated with acquired von Willebrand syndrome," Lupus, vol. 22, no. 14, pp. 1514-1517, 2013.

[11] M. Niiya, K. Niiya, Y. Takazawa et al., "Acquired type 3-like von Willebrand syndrome preceded full-blown systemic lupus erythematosus," Blood Coagulation and Fibrinolysis, vol. 13, no. 4, pp. 361-365, 2002.

[12] J. Pizzuto, R. Ambriz, M. de La Paz Reyna et al., "Acquired von Willebrand's syndrome during autoimmune disorder," Thrombosis and Haemostasis, vol. 42, no. 5, pp. 1523-1528, 1980.

[13] P. A. Poole-Wilson, "Acquired von Willebrand's syndrome and systemic lupus erythematosus," Proceedings of the Royal Society of Medicine, vol. 65, no. 6, pp. 561-562, 1972.
[14] J. V. Simone, J. A. Cornet, and C. F. Abildgaard, "Acquired von Willebrand's syndrome in systemic lupus erythematosus.", Blood, vol. 31, no. 6, pp. 806-812, 1968.

[15] G. A. Soff and D. Green, "Autoantibody to von Willebrand factor in systemic lupus erythematosus," The Journal of Laboratory and Clinical Medicine, vol. 121, no. 3, pp. 424-430, 1993.

[16] J.-F. Viallard, J. L. Pellegrin, C. Vergnes et al., "Three cases of acquired von willebrand disease associated with systemic lupus erythematosus," British Journal of Haematology, vol. 105, no. 2, pp. 532-537, 1999.

[17] H. Yoshida, K. Arai, and M. Wakashin, "Development of acquired von Willebrand's disease after mixed connective tissue disease," The American Journal of Medicine, vol. 85, no. 3, pp. 445-446, 1988.

[18] A. Tiede, J. Priesack, S. Werwitzke et al., "Diagnostic workup of patients with acquired von Willebrand syndrome: a retrospective single-centre cohort study," Journal of Thrombosis and Haemostasis, vol. 6, no. 4, pp. 569-576, 2008.

[19] A. B. Federici, "Acquired von Willebrand syndrome: is it an extremely rare disorder or do we see only the tip of the iceberg?" Journal of Thrombosis and Haemostasis, vol. 6, no. 4, pp. 565$568,2008$.

[20] A. Federici, U. Budde, G. Castaman, J. Rand, and A. Tiede, "Current diagnostic and therapeutic approaches to patients with acquired von Willebrand syndrome: a 2013 update," Seminars in Thrombosis and Hemostasis, vol. 39, no. 2, pp. 191-201, 2013.

[21] S. Kumar, R. K. Pruthi, and W. L. Nichols, "Acquired von Willebrand's syndrome: a single institution experience," American Journal of Hematology, vol. 72, no. 4, pp. 243-247, 2003.

[22] A. Tiede, J. H. Rand, U. Budde, A. Ganser, and A. B. Federici, "How I treat the acquired von Willebrand syndrome," Blood, vol. 117, no. 25, pp. 6777-6785, 2011.

[23] M. Franchini, G. Lippi, and E. J. Favaloro, "Etiology and diagnosis of acquired von Willebrand syndrome," Clinical Advances in Hematology and Oncology, vol. 8, no. 1, pp. 20-24, 2010.

[24] H. Mohri, "Acquired von Willebrand syndrome: features and management," The American Journal of Hematology, vol. 81, no. 8, pp. 616-623, 2006.

[25] A. B. Federici, J. H. Rand, P. Bucciarelli et al., "Acquired von Willebrand syndrome: data from an international registry," Journal of Thrombosis and Haemostasis, vol. 84, no. 2, pp. 345349, 2000.

[26] A. B. Federici, U. Budde, and J. H. Rand, "Acquired von Willebrand syndrome 2004: international registry. Diagnosis and management from online to bedside," Hamostaseologie, vol. 24, no. 1, pp. 50-55, 2004.

[27] M. Franchini and G. Lippi, "Acquired von Willebrand syndrome: an update," American Journal of Hematology, vol. 82, no. 5, pp. 368-375, 2007.

[28] A. B. Federici and P. M. Mannucci, "Diagnosis and management of acquired von Willebrand syndrome," Clinical Advances in Hematology and Oncology, vol. 1, no. 3, pp. 169-175, 2003.

[29] J. Lazarchick and C. Green, "Acquired von Willebrand's disease following bone marrow transplantation," Annals of Clinical and Laboratory Science, vol. 24, no. 3, pp. 211-215, 1994.

[30] J. H. Rand and L. R. Wolgast, "Dos and don'ts in diagnosing antiphospholipid syndrome," in Hematology Am Soc Hematol Educ Program, pp. 455-459, 2012.

[31] U. Budde, F. Bergmann, and J. J. Michiels, "Acquired von Willebrand syndrome: experience from 2 years in a single laboratory compared with data from the literature and an 
international registry," Seminars in Thrombosis and Hemostasis, vol. 28, no. 2, pp. 227-237, 2002.

[32] A. Tiede, "Diagnosis and treatment of acquired von Willebrand syndrome," Thrombosis Research, vol. 130, supplement 2, pp. S2S6, 2012.

[33] J. J. Michiels, U. Budde, M. van der Planken, H. H. D. M. van Vliet, W. Schroyens, and Z. Berneman, "Acquired von Willebrand syndromes: clinical features, aetiology, pathophysiology, classification and management," Best Practice and Research: Clinical Haematology, vol. 14, no. 2, pp. 401-436, 2001.

[34] P. Kasatkar, K. Ghosh, and S. Shetty, "An atypical manifestation of acquired von Willebrand syndrome (AVWS) associated with systemic lupus erythematosus (SLE)," Annals of Hematology, vol. 93, no. 1, pp. 173-175, 2014.

[35] S. Kumar, R. K. Pruthi, and W. L. Nichols, "Acquired von Willebrand disease," Mayo Clinic Proceedings, vol. 77, no. 2, pp. 181-187, 2002.

[36] A. B. Federici, “Therapeutic approaches to acquired von willebrand syndrome," Expert Opinion on Investigational Drugs, vol. 9, no. 2, pp. 347-354, 2000.

[37] J. J. Michiels, Z. Berneman, A. Gadisseur et al., "Immunemediated etiology of acquired von Willebrand syndrome in systemic lupus erythematosus and in benign monoclonal gammopathy: therapeutic implications," Seminars in Thrombosis and Hemostasis, vol. 32, no. 6, pp. 577-588, 2006.

[38] J. A. Kanakry and D. E. Gladstone, "Maintaining hemostasis in acquired von Willebrand syndrome: a review of intravenous immunoglobulin and the importance of rituximab dose scheduling," Transfusion, vol. 53, no. 8, pp. 1730-1735, 2013.

[39] E. Mazoyer, O. Fain, R. Dhote, and Y. Laurian, "Is rituximab effective in acquired von Willebrand syndrome?" British Journal of Haematology, vol. 144, no. 6, pp. 967-968, 2009.

[40] H. Mohri, S. Motomura, H. Kanamori et al., "Clinical significance of inhibitors in acquired von Willebrand syndrome," Blood, vol. 91, no. 10, pp. 3623-3629, 1998.

[41] A. B. Federici, "Use of intravenous immunoglobulin in patients with acquired von Willebrand syndrome," Human Immunology, vol. 66, no. 4, pp. 422-430, 2005.

[42] P. J. J. van Genderen, J. J. Michiels, J. J. Bakker, and M. B. Van't Veer, "Effectiveness of high-dose intravenous gamma globulin therapy in acquired von Willebrand's disease," Vox Sanguinis, vol. 67, no. 1, pp. 14-17, 1994.

[43] A. B. Federici, F. Stabile, G. Castaman, M. T. Canciani, and P. M. Mannucci, "Treatment of acquired von Willebrand syndrome in patients with monoclonal gammopathy of uncertain significance: comparison of three different therapeutic approaches," Blood, vol. 92, no. 8, pp. 2707-2711, 1998.

[44] A. Wiestner, H. J. Cho, A. S. Asch et al., "Rituximab in the treatment of acquired factor VIII inhibitors," Blood, vol. 100, no. 9, pp. 3426-3428, 2002.

[45] W. Barcellini and A. Zanella, "Rituximab therapy for autoimmune haematological diseases," European Journal of Internal Medicine, vol. 22, no. 3, pp. 220-229, 2011. 


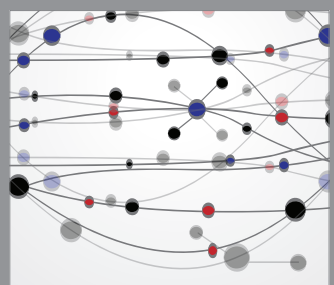

The Scientific World Journal
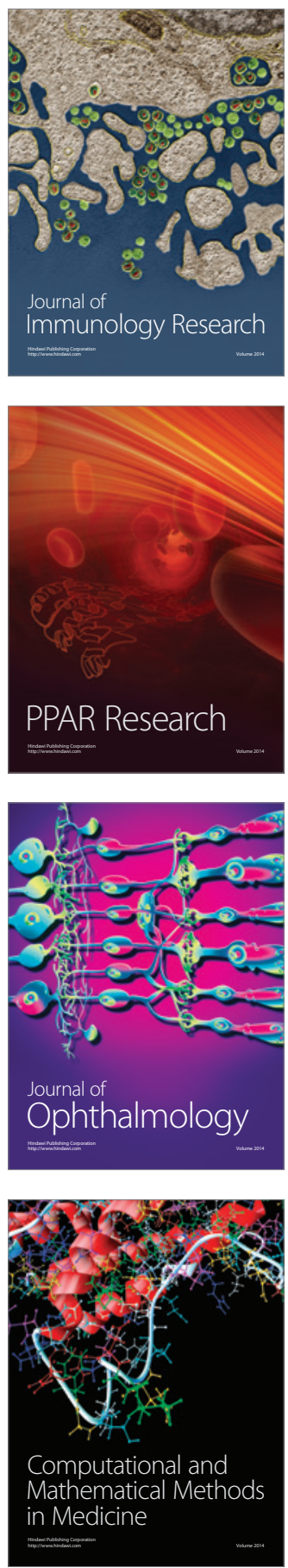

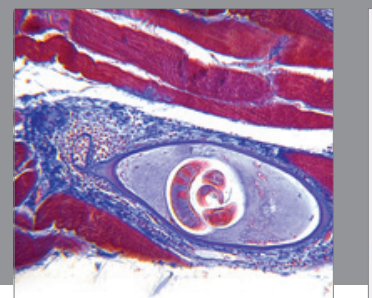

Gastroenterology

Research and Practice
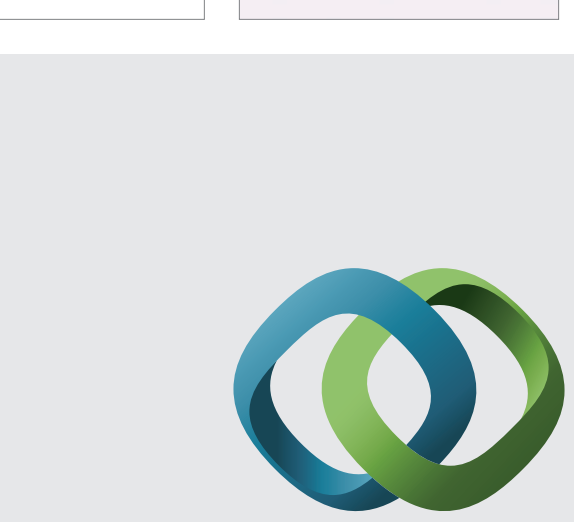

\section{Hindawi}

Submit your manuscripts at

http://www.hindawi.com
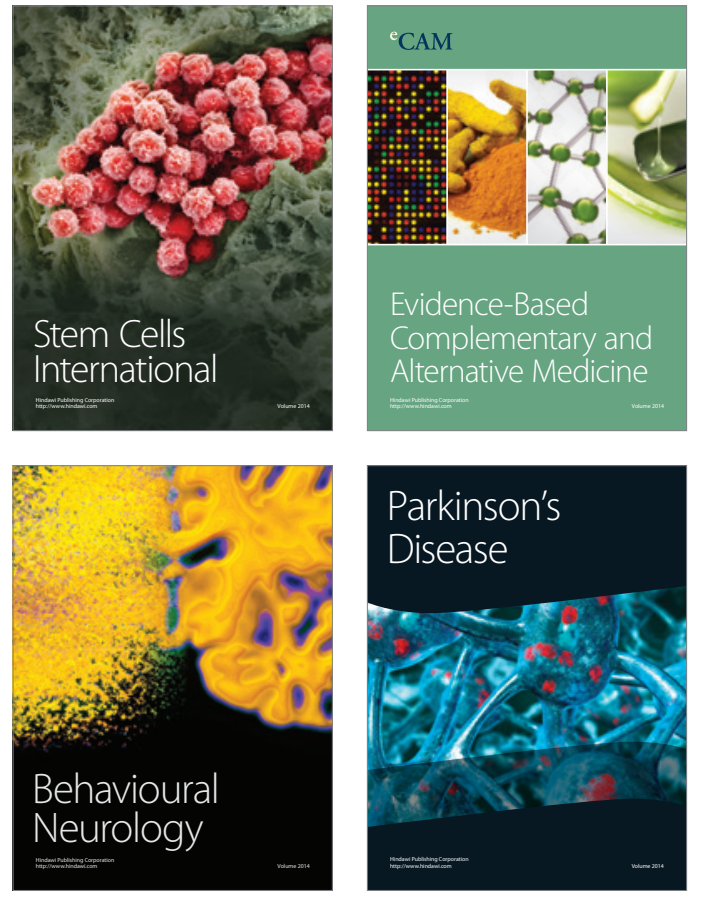
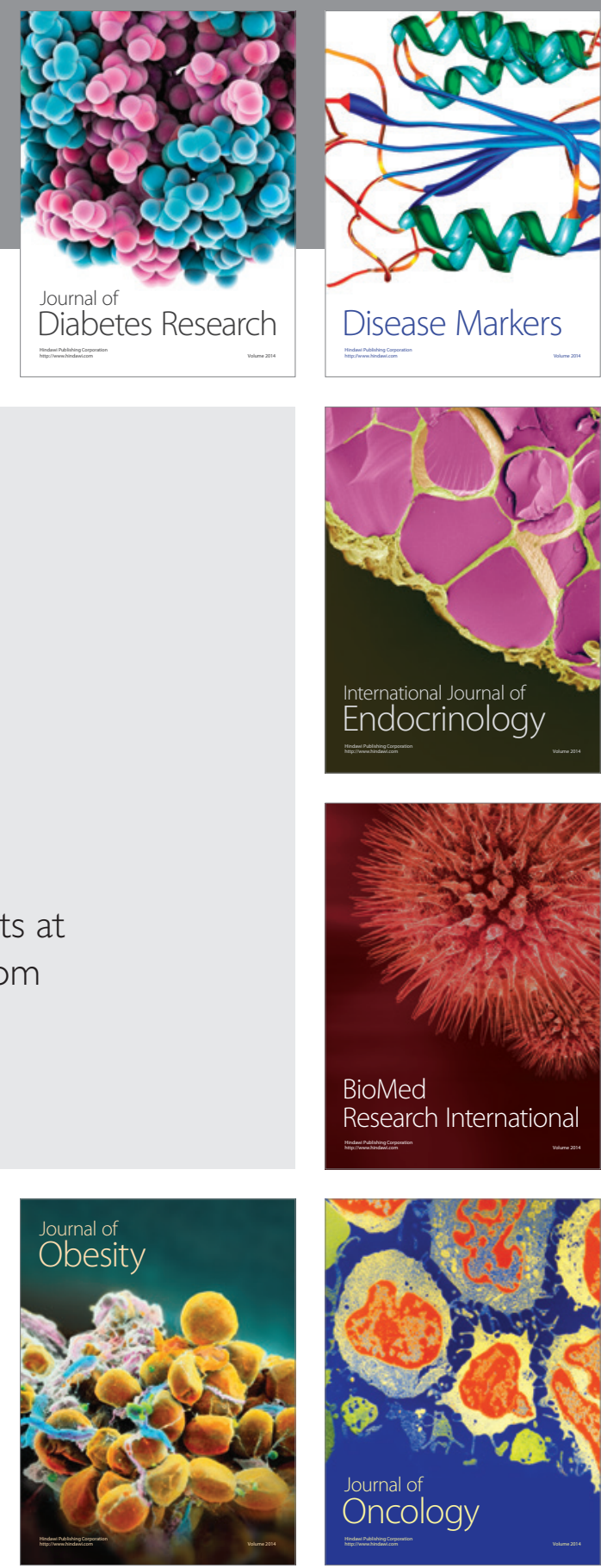

Disease Markers
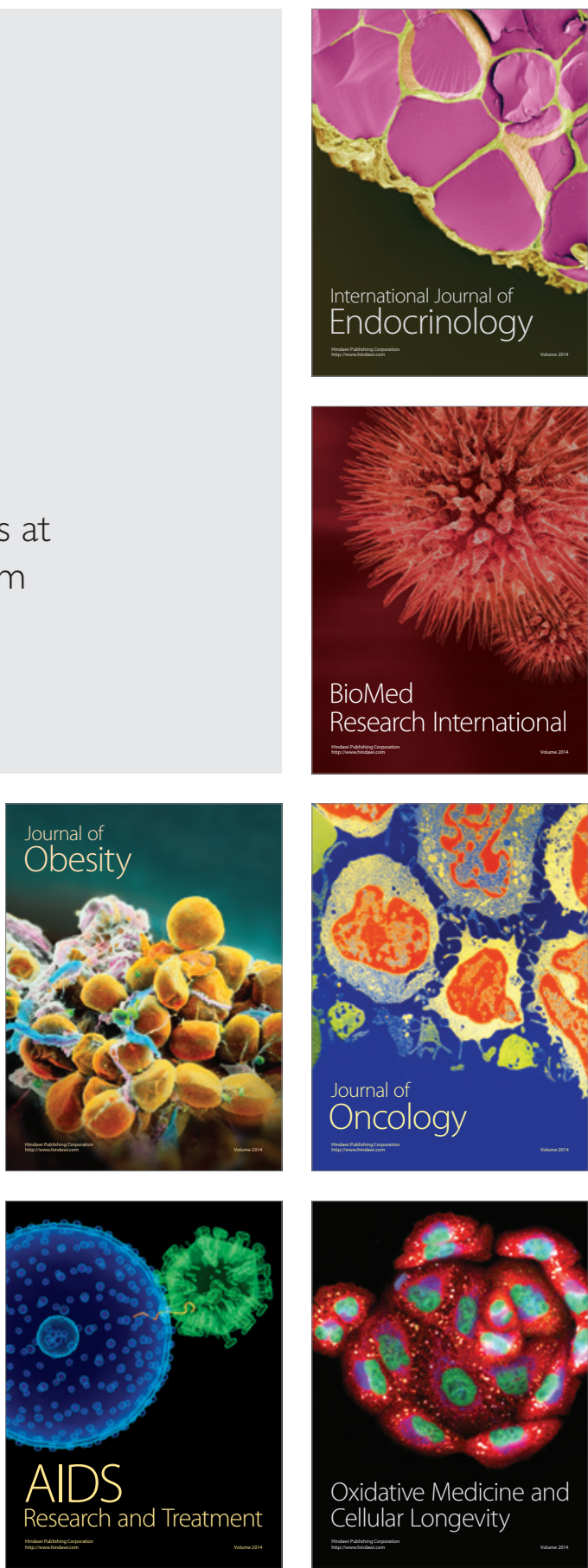